\title{
Factors Associated with Meeting Obstetric Care Consensus Guidelines for Nulliparous, Term, Singleton, Vertex Cesarean Births
}

\author{
Tiffany Wang, $\mathrm{MD}^{1,2}$ Inga Brown, $\mathrm{MD}^{1,2}$ Jim Huang, $\mathrm{PhD}^{3}$ Tetsuya Kawakita, MD, MS ${ }^{1}$ \\ Michael Moxley, MD² \\ ${ }^{1}$ Department of Obstetrics and Gynecology, MedStar Washington \\ Hospital Center, Washington, District of Columbia \\ ${ }^{2}$ Department of Obstetrics and Gynecology, Virginia Hospital Center, \\ Arlington, Virginia \\ ${ }^{3}$ Department of Biostatistics, MedStar Health Research Institute, \\ Hyattsville, Maryland \\ AJP Rep 2021;11:e142-e146.

\begin{abstract}
Address for correspondence Tiffany Wang, MD, Department of Obstetrics and Gynecology, MedStar Washington Hospital Center, 110 Irving Street Northwest, Washington, DC 20010 (e-mail: tiffanylwang810@gmail.com).
\end{abstract}

\begin{abstract}
Keywords

- cesarean birth

- nulliparous

- term

- singleton

- vertex

- obstetrics

- labor

Objective This study aimed to identify factors associated with meeting the Obstetric Care Consensus (OCC) guidelines for nulliparous, term, singleton, and vertex (NTSV) cesarean births.

Materials and methods This was a retrospective case control study of women with NTSV cesarean births between January 2014 and December 2017 at single tertiary care center. Demographics and clinical characteristics were compared between women with NTSV cesarean births which did or did not meet OCC guidelines. A multivariable logistic regression model was used to evaluate the effect of each variable on the odds of meeting OCC guidelines.

Results There were 1,834 women with NTSV cesarean births of which 744 (40.6\%) met OCC guidelines for delivery and 1,090 (59.4\%) did not. After controlling for confounding factors, the odds of meeting OCC guidelines were increased for in-house providers managing with residents (adjusted odds ratio $[\mathrm{aOR}]=2.03,95 \%$ confidence interval $[\mathrm{Cl}]: 1.44-2.87)$ and without residents $(\mathrm{aOR}=1.66,95 \% \mathrm{Cl}: 1.30-2.12$ ), compared with non-in-house providers managing without residents. There was no significant difference in the odds of meeting OCC guidelines for in-house providers managing with or without residents ( $\mathrm{aOR}=1.23,95 \% \mathrm{Cl}: 0.84-1.79$ ).

Conclusion After adjusting for confounding factors, in-house provider coverage, regardless of resident involvement, is associated with increased odds of NTSV cesarean births meeting OCC guidelines.
\end{abstract}

\section{Key Points}

- Frequency of adherence to OCC guidelines for NTSV cesarean births was $40.6 \%$.

- Neither patient demographics nor comorbidities was associated with the odds of meeting OCC guidelines.

- In-house providers are associated with increased odds of meeting OCC guidelines.

received

May 18,2020

accepted after revision

October 8, 2021
DOI https://doi.org/ 10.1055/s-0041-1740563. ISSN 2157-6998.

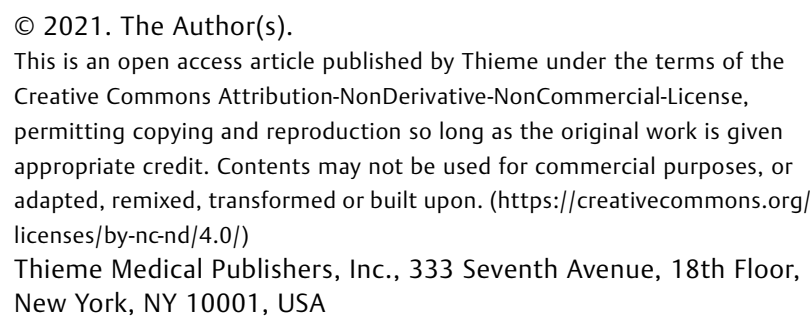
appropriate credit. Contents may not be used for commercial purposes, or adapted, remixed, transformed or built upon. (https://creativecommons.org/ licenses/by-nc-nd/4.0/)

Thieme Medical Publishers, Inc., 333 Seventh Avenue, 18th Floor, New York, NY 10001, USA 
The overall United States cesarean birth rate has been approximately $32 \%$ since $2010 .^{1}$ The increased morbidity associated with cesarean compared with vaginal birth is well known, with additional complications such as uterine rupture, abnormal placentation, and obstetrical hemorrhage associated with repeat cesarean birth. ${ }^{2,3}$ The U.S. primary cesarean birth rate closely parallels, and is considered an important driver of, the overall cesarean birth rate. As such, there has been ongoing interest to reduce the primary cesarean birth rate in an effort to lower the overall cesarean birth rate and to decrease the downstream complications of repeat cesarean birth. ${ }^{4-7}$

In 2014, the American Congress of Obstetricians and Gynecologists (ACOG) and Society for Maternal-Fetal Medicine (SMFM) jointly published their Obstetric Care Consensus (OCC) guidelines which provide strategies to safely prevent the primary cesarean birth. Their publication addresses guidelines for diagnosing labor arrest in the first or second stage of labor and provides recommendations on managing intrapartum fetal heart rate abnormalities and fetal macrosomia. ${ }^{5}$ ACOG and SMFM also specifically comment on the wide variation in the nulliparous, term, singleton, and vertex (NTSV) cesarean birth rate in hospitals across the country. ${ }^{5}$ Despite these recommendations in the OCC guidelines, factors which may influence adherence to those guidelines are not well known. Previous studies have focused on factors which influence the primary cesarean birth rate, ${ }^{8-11}$ but data are scant regarding whether adherence to OCC guidelines may play a role specifically in preventing the first cesarean birth in women with NTSV pregnancies. The primary purpose of this study was therefore to identify factors associated with meeting OCC guidelines for NTSV cesarean births.

\section{Study Design}

This was a single-center, retrospective case control study of all women with NTSV cesarean births from January 2014 to December 2017 at Virginia Hospital Center, a 350-bed community teaching hospital in Arlington, VA, which serves patients in the greater District of Columbia and Northern Virginia area. The hospital averages approximately 5,000 deliveries yearly. This study was approved by the institution's Clinical Research Committee as exempt from Institutional Review Board review. During this time period, there were significant educational efforts by hospital leadership to increase awareness of the OCC guidelines published in 2014 and reaffirmed in 2016; these efforts included regular presentation of data and guidelines at departmental meetings, interdisciplinary drills and training (such as review of fetal heart rate interpretation and management), and establishment of a chain of command when concerns about patient management arose from any patient care team member.

Women with NTSV cesarean births were identified through the hospital's electronic medical record using hospital metric data gathered monthly in a prospective manner by hospital administrative personnel. The accuracy of the data was verified independently by the first and second authors. Demographic data including the provider model for the patient, maternal race, maternal age, and gestational age were collected. Clinical characteristics including prepregnancy body mass index (BMI) in $\mathrm{kg} / \mathrm{m}^{2}$, and the presence of pregestational diabetes, gestational diabetes, chronic hypertension, gestational hypertension, preeclampsia, or smoking were also collected.

The provider model for each patient was determined to either be (1) an in-house provider managing with residents ( $\sim 10$ providers), (2) an in-house provider managing without residents ( $\sim 30-40$ providers), or (3) a non-in-house provider managing without residents ( $\sim 25-30$ providers). An individual provider generally practiced within their one practice model; the rare exception includes a provider who usually covers as a non-in-house provider managing without residents, but on occasion, took call as a hospitalist and thus served as an in-house provider managing with residents. In this scenario, the practice model which that provider took call under was the classification used for analysis. Of note, each practice model has predetermined among themselves their in-house coverage. Per the institution's policy, in-house providers are required to be in the hospital 24 hours a day, and non-in-house providers are only required to be in the hospital when the patient is in active labor or if the patient is being augmented with oxytocin. Resident involvement in labor has been limited to one specific in-house provider group to clearly delineate expectations for residents, labor, and delivery staff, and covering providers. While residents may assist in obstetrical emergencies of other practice groups, such as postpartum hemorrhages, they are not involved in the labor course or decision-making surrounding labor management in these other practice groups.

A hospital quality review committee, comprised of attending obstetric physician representatives from each of the three provider models, a lead obstetric attending physician, and a member of nursing leadership, determined if the indication for each delivery met OCC guidelines for NTSV cesarean birth. The OCC guidelines included the following: (1) diagnosis of failed induction of labor in the latent phase only with ruptured membranes and oxytocin for at least 12 hours without cervical change; (2) diagnosis of active phase arrest only for women greater than or equal to $6 \mathrm{~cm}$ dilated with ruptured membranes, without cervical change given four hours of adequate contractions or 6 hours of inadequate contractions based on assessment of the Montevideo units; (3) allowing at least 2 hours of pushing for multiparous women and three hours for nulliparous women, with an additional hour allowed if there was an epidural used; and (4) reserving cesarean birth for suspected fetal macrosomia only for estimated fetal weight of greater than 4,500 or greater than $5,000 \mathrm{~g}$ in women with and without diabetes, respectively. An NTSV cesarean birth to be determined to not meet OCC guidelines if the above clinical guidelines were not met or there was not enough documentation in the electronic medical record to make such an assessment; in addition, all reviewers on the hospital quality review committee must unanimously agree that the delivery did not meet OCC guidelines.

Bivariate analysis was performed to assess the differences in demographic and clinical characteristics between the groups 
which did and did not meet OCC guidelines. The Student's ttest, unbalanced analysis of variance (ANOVA), Chi-square test, and Fisher's exact test were applied when appropriate. A pvalue of less than 0.05 was considered statistically significant. A multivariable logistic regression model was used to evaluate the effect of each variable on the odds of meeting OCC guidelines, controlling for provider model, maternal race, maternal age, gestational age, prepregnancy BMI, pregestational diabetes, gestational diabetes, chronic hypertension, gestational hypertension, preeclampsia, and smoking. The adjusted odds ratios (aORs) and 95\% confidence intervals (CIs) were estimated. All statistical calculations were performed using SAS (version 9.4, Cary, NC).

\section{Results}

There were 1,834 women with NTSV cesarean births in our cohort of which 744 (40.6\%) met OCC guidelines for NTSV cesarean birth and 1,090 (59.4\%) did not. Most demographic and clinical characteristics ( - Table $\mathbf{1}$ ) were similar between the two groups. However, the provider model distribution of the patients differed, with $51 \%$ (93 out of 183 ), $47 \%$ (178 out of 379 ), and $37 \%$ (472 out of 1,271 ) of NTSV cesarean births performed by in-house providers managing with residents, in-house providers managing without residents, and non-inhouse providers managing without residents meeting OCC guidelines for cesarean birth, respectively $(p<0.01)$.

Compared with non-in-house providers managing without residents, the odds of meeting OCC guidelines were increased for in-house providers managing with residents (aOR $=2.03,95 \% \mathrm{CI}: 1.44-2.87$ ) and for in-house providers managing without residents $(\mathrm{aOR}=1.66,95 \% \mathrm{CI}: 1.30-2.12)$, after controlling for confounding factors. There was no significant difference in the odds of meeting OCC guidelines for in-house providers managing with or without residents (aOR $=1.23,95 \% \mathrm{CI}: 0.84-1.79)$.

Compared with NTSV cesarean births which did not meet OCC guidelines, there was a slightly increased odds of

Table 1 Demographic and clinical characteristics

\begin{tabular}{|c|c|c|c|c|}
\hline Variable & $\begin{array}{l}\text { Met OCC } \text { guidelines }^{a} \\
(n=744)\end{array}$ & $\begin{array}{l}\text { Did not meet OCC } \\
\text { guidelines }^{\text {a }}(n=1,090)\end{array}$ & $p$-Value ${ }^{b}$ & $\begin{array}{l}\text { aOR ( } 95 \% \mathrm{Cl} \text { ) of meeting } \\
\text { OCC guidelines }\end{array}$ \\
\hline \multicolumn{5}{|l|}{ Provider model ${ }^{\mathrm{C}}$} \\
\hline $\begin{array}{l}\text { In-house providers } \\
\text { managing with residents }\end{array}$ & $93(12.5)$ & $90(8.3)$ & \multirow[t]{3}{*}{$<0.01$} & $2.03(1.44-2.87)$ \\
\hline $\begin{array}{l}\text { In-house providers managing } \\
\text { without residents }\end{array}$ & $178(24.0)$ & $201(18.4)$ & & $1.66(1.30-2.12)$ \\
\hline $\begin{array}{l}\text { Non-in-house providers } \\
\text { managing without residents }\end{array}$ & $472(63.5)$ & $799(73.3)$ & & (Reference group) \\
\hline \multicolumn{5}{|l|}{ Maternal race } \\
\hline White/European & $347(46.6)$ & $511(46.9)$ & \multirow[t]{5}{*}{0.18} & (Reference group) \\
\hline Black/African & $105(14.1)$ & $114(10.5)$ & & $1.24(0.90-1.70)$ \\
\hline Hispanic & $41(5.5)$ & $67(6.2)$ & & $0.79(0.51-1.23)$ \\
\hline Asian & $108(14.5)$ & $172(15.8)$ & & $0.83(0.62-1.10)$ \\
\hline Unknown & $143(19.2)$ & $226(20.7)$ & & $0.92(0.70-1.20)$ \\
\hline Maternal age & $32.1 \pm 5.6$ & $31.7 \pm 5.1$ & 0.13 & $1.02(1.00-1.04)^{d}$ \\
\hline Gestational age in weeks & $39.8 \pm 1.2$ & $39.9 \pm 1.1$ & 0.25 & $0.98(0.90-1.07)$ \\
\hline Prepregnancy BMI & $26.6 \pm 7.9$ & $27.0 \pm 7.9$ & 0.29 & $0.99(0.97-1.00)$ \\
\hline \multicolumn{5}{|l|}{ Diabetes } \\
\hline Pregestational diabetes & $12(1.6)$ & $11(1.0)$ & 0.25 & $1.72(0.74-4.07)$ \\
\hline Gestational diabetes & $58(7.8)$ & $81(7.4)$ & 0.77 & $1.00(0.70-1.44)$ \\
\hline \multicolumn{5}{|l|}{ Hypertensive disorders } \\
\hline Chronic hypertension & $16(2.2)$ & $16(1.5)$ & 0.27 & $1.68(0.78-3.62)$ \\
\hline Gestational hypertension & $45(6.1)$ & $46(4.2)$ & 0.08 & $1.57(1.01-2.43)$ \\
\hline Preeclampsia & $54(7.3)$ & $72(6.6)$ & 0.59 & $1.08(0.74-1.58)$ \\
\hline Smoking & $1(0.1)$ & $5(0.5)$ & 0.23 & $0.20(0.02-1.74)$ \\
\hline
\end{tabular}

Abbreviations: aOR, adjusted odds ratio; BMI, body mass index $\left(\mathrm{kg} / \mathrm{m}^{2}\right)$; $\mathrm{Cl}$, confidence interval; OCC, Obstetric Care Consensus.

${ }^{a}$ Data are reported as $n(\%)$ or mean \pm standard deviation.

${ }^{b} p$-Values indicate the statistical testing result based on bivariate analysis.

'There was one observation with missing information on provider model.

${ }^{\mathrm{d}}$ Age increments of every 5 years. 
gestational hypertension in women with NTSV cesarean births which met OCC guidelines $(\mathrm{aOR}=1.57$ with $95 \% \mathrm{CI}$ : $1.01-2.43)$.

\section{Discussion}

In our cohort of 1,834 women with NTSV cesarean births, we found that the frequency of adherence to OCC guidelines was $40.6 \%$. Factors associated with adherence to OCC guidelines included the patient's provider model and the presence of gestational hypertension.

Given the increased morbidity with multiple repeat cesarean births, there has been an increased focus on preventing the primary cesarean birth, primarily in low-risk NTSV pregnancies. The 2014 OCC guidelines published by ACOG and SMFM attempted to standardize guidelines for clinicians in making decisions on labor management for these patients. However, the results of our study indicate that in clinical practice, the OCC guidelines are not always followed prior to proceeding with NTSV cesarean birth, with only $40.6 \%$ of our cohort of women with NTSV cesarean births meeting OCC guidelines. There may be several potential reasons for this, including provider nonawareness of the OCC guidelines, limited resources to allow for adherence to OCC guidelines, various patient or provider characteristics, or other clinical scenarios not captured in our data.

In addition, it does not appear that at least in our cohort, demographic characteristics (such as maternal race, maternal age, or gestational age) or the presence of major medical comorbidities (such as prepregnancy BMI, pregestational diabetes, gestational diabetes, chronic hypertension, preeclampsia, or smoking) affected the odds of meeting OCC guidelines. Although the presence of gestational hypertension was associated with a slightly increased statistical odds of meeting OCC guidelines ( $\mathrm{aOR}=1.57$ with $95 \% \mathrm{CI}$ : $1.01-$ 2.43 ), this difference is likely not clinically significant.

Previous studies on obstetric hospitalists who provide continuous in-house care on labor and delivery units have resulted in mixed results on cesarean delivery rates, with some studies ${ }^{12-14}$ demonstrating that hospitalists have lower cesarean delivery rates, and other studies ${ }^{15-17}$ demonstrating that hospitalists have similar or higher cesarean delivery rates compared with other practice models. However, previous studies have not specifically looked at NTSV cesarean rates and OCC guideline adherence in hospitalist or other practice models of care. Our study shows that the provider model of the covering physician may play an important role in whether or not OCC guidelines are met. The three provider models in our study (in-house providers managing with residents, in-house providers managing without residents, and non-in-house providers managing without residents) had significantly different rates of NTSV cesarean births meeting OCC guidelines. After adjusting for possible confounding factors that may account for differences among these groups, in-house provider coverage, regardless of resident involvement in management, was still associated with increased odds of NTSV cesarean births meeting OCC guidelines. The presence of an in-house pro- vider likely allows for increased opportunities to evaluate the patient in-person in a timely fashion which may influence the clinical assessment of a patient's progress in labor, fetal resuscitative measures undertaken, or patient counseling practices, all of which may increase the odds of meeting OCC guidelines when managing a patient with an NTSV pregnancy.

\section{Strengths and Limitations}

Strengths of our study include our inclusion of over 1,800 patients and representation of a wide variety of provider models. In addition, the hospital studied is a tertiary referral center with high volume and acuity. Each NTSV cesarean birth was also reviewed by a quality review committee with strict criteria for determining whether or not the OCC guidelines were met. However, our study is limited by its potential nongeneralizability in nontertiary referral centers where midwife care of patients or the solo practitioner model may be more common. In addition, despite inclusion of over 1,800 patients in this study, an increased sample size would certainly provide additional power to assess for smaller differences in factors which may affect adherence to OCC guidelines. Furthermore, the educational initiatives as outlined previously may have been differentially distributed more frequently to certain provider groups rather than others. Therefore, the effect of these educational initiatives on adherence to OCC guidelines cannot be elucidated from our study. Finally, it is also limited by its retrospective nature, namely, that it would also be impractical to randomly assign patients to providers of different provider models given restrictions with insurance coverage and reimbursement.

\section{Conclusion}

In conclusion, our study found that in-house provider coverage, regardless of resident involvement in patient management, is associated with increased odds of NTSV cesarean births meeting OCC guidelines. Our study raises important clinical questions on the potential role of an in-house provider in helping to more closely adhere to OCC guidelines. Ultimately, this may be one strategy that can be implemented to safely reduce the NTSV cesarean birth rate over time.

\section{Conflict of Interest}

The authors report no financial or commercial conflicts of interest. This study did not receive any funding from external or internal sources.

\section{References}

1 Martin JA, Hamilton BE, Osterman MJK, Driscoll AK, Drake P. Births: final data for 2016. Natl Vital Stat Rep 2018;67(01): 1-55

2 Gregory KD, Jackson S, Korst L, Fridman M. Cesarean versus vaginal delivery: whose risks? Whose benefits?. Am J Perinatol 2012;29(01):7-18 
3 Silver RM, Landon MB, Rouse DJ, et al; National Institute of Child Health and Human Development Maternal-Fetal Medicine Units Network. Maternal morbidity associated with multiple repeat cesarean deliveries. Obstet Gynecol 2006;107(06):1226-1232

4 Osterman MJ, Martin JA. Trends in low-risk cesarean delivery in the United States, 1990-2013. Natl Vital Stat Rep 2014;63(06):1-16

5 American College of Obstetricians and Gynecologists and Society for Maternal Fetal Medicine. Obstetric care consensus no. 1: safe prevention of the primary cesarean delivery. Obstet Gynecol 2014;123(03):693-711

6 Spong CY, Berghella V, Wenstrom KD, Mercer BM, Saade GR. Preventing the first cesarean delivery: summary of a joint Eunice Kennedy Shriver National Institute of Child Health and Human Development, Society for Maternal-Fetal Medicine, and American College of Obstetricians and Gynecologists Workshop. Obstet Gynecol 2012;120(05):1181-1193

7 Zhang J, Troendle J, Reddy UM, et al; Consortium on Safe Labor. Contemporary cesarean delivery practice in the United States. Am J Obstet Gynecol 2010;203(04):326.e1-326.e10

8 Pasko DN, McGee P, Grobman WA, et al; Eunice Kennedy Shriver National Institute of Child Health and Human Development (NICHD) Maternal-Fetal Medicine Units (MFMU) Network. Variation in the nulliparous, term, singleton, vertex cesarean delivery rate. Obstet Gynecol 2018;131(06):1039-1048

9 Declercq E, Menacker F, Macdorman M. Maternal risk profiles and the primary cesarean rate in the United States, 1991-2002. Am J Public Health 2006;96(05):867-872
10 Spong CY. Prevention of the first cesarean delivery. Obstet Gynecol Clin North Am 2015;42(02):377-380

11 Barber EL, Lundsberg LS, Belanger K, Pettker CM, Funai EF, Illuzzi $\mathrm{JL}$. Indications contributing to the increasing cesarean delivery rate. Obstet Gynecol 2011;118(01):29-38

12 Iriye BK, Huang WH, Condon J, et al. Implementation of a laborist program and evaluation of the effect upon cesarean delivery. Am J Obstet Gynecol 2013;209(03):251.e1-251.e6

13 Iriye BK. Impact of obstetrician/gynecologist hospitalists on quality of obstetric care (cesarean delivery rates, trial of labor after cesarean/vaginal birth after cesarean rates, and neonatal adverse events). Obstet Gynecol Clin North Am 2015;42(03): 477-485

14 Nijagal MA, Kuppermann M, Nakagawa S, Cheng Y. Two practice models in one labor and delivery unit: association with cesarean delivery rates. Am J Obstet Gynecol 2015;212(04):491. e1-491.e8

15 Corey J, Cuartas K, Leidlein C, Pineles B, Wagner S. The influence of academic hospitalists on labor and delivery outcomes. Gynecol Obstet Invest 2020;85(04):352-356

16 Srinivas SK, Small DS, Macheras M, Hsu JY, Caldwell D, Lorch S. Evaluating the impact of the laborist model of obstetric care on maternal and neonatal outcomes. Am J Obstet Gynecol 2016;215 (06):770.e1-770.e9

17 Feldman DS, Bollman DL, Fridman M, et al. Do laborists improve delivery outcomes for laboring women in California community hospitals? Am J Obstet Gynecol 2015;213(04):587.e1-587.e13 